\title{
Overcoming local constraints when developing renewable energy systems for the electrification of remote areas in Africa
}

\author{
Joseph Kenfack ${ }^{1, *}$, Joseph Voufo $^{1}$, Paul Salomon Ngohe Ekam ${ }^{1}$, Jeanine K. Lewetchou ${ }^{2}$, \\ and Urbain Nzotcha ${ }^{1}$ \\ ${ }^{1}$ University of Yaounde I, Polytechnic, Yaounde, Cameroon \\ ${ }^{2}$ University of Dschang, Dschang, Cameroon
}

Received: 29 May 2019 / Accepted: 26 September 2019

\begin{abstract}
Sub Saharan Africa has a great renewable energy potential. Rural areas are suffering from poor energy access. Some systems designed to address this issue are still faced with some difficulties. Appropriate approaches and energy plant development will help remote areas to address the issue of electricity access. The current development of some micro hydro and micro solar energy plants is of poor quality and maintenance, sometimes resulting in failures. There are also some common mistakes made when promoting (designing) an energy system in an African environment. Identifying issues from local constraints and lessons learned will contribute to determining the appropriate sizing, technology and tools to correctly develop micro hydro and micro solar energy plants.
\end{abstract}

\section{Introduction}

Sub Saharan Africa is sunny, has an extensive area with high rainfall, and is not particularly windy. The continent, therefore, has an important renewable energy potential, primarily in the forms of solar, hydro, geothermal and biomass energy. As demonstrated in the mining sector [1], the preparation for the continent to address the issue in energy sector is crucial. For a number of reasons, this important potential is still suffering from poor development or inappropriate development. The capacity developed thus far in remote areas is still suffering from poor quality, leading to poor efficiency and experience. The main cause of the poor use of renewable energy is, among other issues, the approach, the standards that do not necessarily match the local environmental and social conditions. In addition, the optimal methods to appropriately implement the required technology have yet to be fully addressed. There are also some common mistakes we often make when designing the systems.

Based on field experience, the purpose of this paper is to discuss some common errors made when establishing programmes and when designing micro-solar power plants in Africa. From the issues identified, this paper proposes how to address them and how to avoid repeating such

\footnotetext{
* e-mail: joskenfack@yahoo.fr
}

errors in the future. Based on some case studies in Cameroon and the Republic of Congo, actions to avoid some errors and hence sustain appropriate solar energy technology development initiatives are suggested. This paper will also address errors and the problems actually faced and recommend additional actions for mitigation and significant improvement in hydro and solar energy infrastructures in remote areas where the promotion of renewable energy and energy efficiency are critical for poverty alleviation.

\section{Methods}

An assessment has been done for West Africa concerning hydropower [2]. But it concerns large hydro and does not focus on remote area. We collected general data from international organizations in order to describe the general environment of the countries. We collected the specific data in the field from a number of broken micro power plants. We analysed the reasons for failures and developed solutions. To ensure the sustainability of the approach, strength, weaknesses, opportunity and threat (SWOT) analysis of the current initiatives was conducted, leading to a new approach and methods that are appropriate for micro renewable energy plant development in addition to what has been suggested thus far $[3,4]$. The approach is different from what is currently recommended in developed countries [5]. 


\section{Context of remote areas in Africa}

The general context of remote areas in Africa is most often not easily understood. The energy infrastructure and societal structures are not as well-known as, for example, those in the Unites States [4]. Many unusual obstacles must be overcome in the development of sustainable projects.

\subsection{Literacy in the continent}

From the data released by the UNESCO Institute for Statistics [6], literacy rates for adults and youth continue to rise throughout the world. Young people in developing countries are making the strongest gains. Despite these gains, up to $65 \%$ of people in some countries cannot read or write [7]. This is detrimental to the development of projects in Africa, as most of the programmes are in foreign languages. Even if the use of local language is adopted, we might still face some problems because most of these are not written languages.

The continent as a whole has the lowest literacy rates in the world [7]. Improving and/or accounting for literacy is crucial for the capacity building of stakeholders. Although a specific technical literacy (Thomas Young et al. [8]) approach can be adopted in Africa context, special attention should be paid with respect to those involved in a given project to make them comfortable while overseeing it. When projects involve people, who cannot easily read and/or write in the working language, knowledge transmission problems become an obstacle. This means that from the conception phase, the projects should be oriented to the local people. Working in the local language is therefore necessary [9]. Furthermore, specific tools or knowledge transmission methods should be evaluated to ensure consideration of the local culture and beliefs. For the learning process itself, we should take into account the fact that human behaviour is society dependent. This means that even if we consider the 8 different learning styles, ${ }^{1}$ for instance, we should still perform a socioeconomic study to ensure that the training programme matches the environment. The linguistic learning style is less recommended because it relies on linguistic skills including reading, writing, listening, or speaking, even if, not surprisingly, some of the best teachers and professors are linguistic learners. It is in the nature of the profession. The culture of reading and writing in African culture still has room for improvement. A wellknown proverb in the continent from Amadou Ampâté Bâ says "In Africa, when an old man dies, it's a library burning". 2

The naturalist learns by working with and experiencing nature. This approach will be excellent when developing a project, right from the early stages. Here, the learner loves experiences, loves observing the world around him, and

\footnotetext{
${ }^{1}$ http://www.skillsyouneed.com/rhubarb/fingerprints-learningstyles.html (accessed July 10, 2016)

2 https://chocolatnegro.wordpress.com/2012/06/06/in-africawhen-an-old-man-dies-its-a-library-burning/ (accessed August 7, 2016)
}

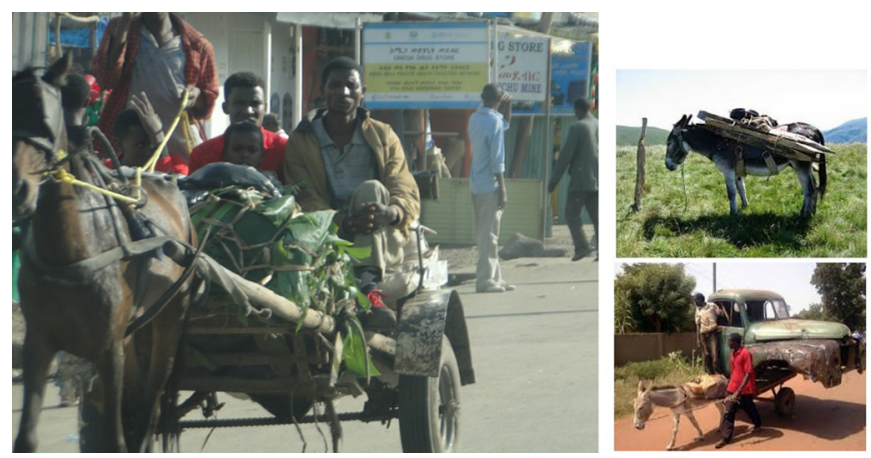

Fig. 1. Transport in some remote areas (photo J. Kenfack in Ethiopia).

best acquires information or knowledge through experimentation. This is similar to the kinaesthetic learner who learns best by actually doing something. Although it can be used during plant construction, this style is best suited for maintenance. Those who cannot read and/or write might be very good visual or spatial learners. They best learn from diagrams, pictures, graphs and objects. These people tend to be technically oriented and might be very good for plant equipment.

The idea in the rural area environment is to avoid complex equations. This means that there might not be a room for the logical or mathematical learner. Even if we still need this ability, we should work to simplify things. Many people also learn by relating to others. They are better when they share stories, work in teams, and compare their ideas to the ideas of others. That is why we should treat the learners as a team so that they can help one another, especially for when the teacher is no longer available. A village involvement approach will help them to take ownership of the project and will allow them to put together all the various competencies and come out with a very good project. If possible and right before the capacity building, we should design a method to determine the profile (learning style) of the learners in order to ensure the success of the project. This requires a socioeconomic study.

\subsection{Poor roads and means of transport}

One of the characteristics of rural areas is the poor means of transport, namely, the roads. This leads to ingenious approaches using manpower or animal power as depicted in Figure 1.3,4

In some fortunate areas, roads do exist. However, they are not always in good condition, especially during the rainy season (Fig. 2). Logistics is a large issue that must be properly addressed when designing a project.

This has an important impact when planning the development of or operating a plant. Transportation is hence another significant issue. It is obvious that the use of trucks for transportation or cranes for handling the

\footnotetext{
$\overline{3}$ http://www.baladane.com/fr/animations-anes (January 4 2016)

${ }^{4}$ http://etlaterreenfanta.blog50.com/archives/2009/03/index3.html (accessed January 4, 2016)
} 


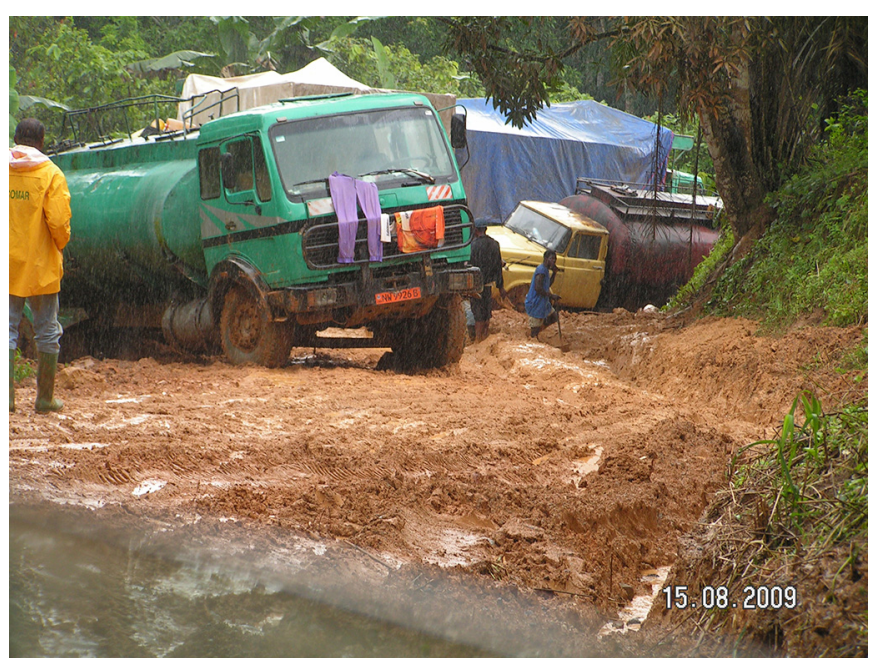

Fig. 2. Poor road for truck (untarred) during the rainy season (Photo J. Kenfack in Mbongue Cameroon).

equipment should be minimized or abandoned, especially in cases where there is no road suitable even for off-road vehicles. Figures 1 and 2, for instance, offer insight into how people manage in some areas.

Each region in the continent has its own difficulties, and we should therefore consider them on a case-by-case basis.

The railway network is also very poor in general and does not simply exist in some countries (Chad, Central African Republic for instance).

The case of Cameroon for instance is not very different from that of an average African country. It has an overall length of $1104 \mathrm{~km}$ of $1000 \mathrm{~mm}$, which is very small compared to the area of the country, which is $475000 \mathrm{~km}^{2}$ with more than twenty million people. The last kilometre was completed since 1974, and nothing else has been done so far.

From the situation described above, we should make sure we tackle all the logistics problems. We can, for instance, decide to carry the spare parts and ensure the assembly on site or in the vicinity. We can also make a plan and ensure that some key activities on site take place during the dry season.

Another issue to address in the field of communication is electronic communication (telephones and Internet, digital tablets). From some statistics, ${ }^{5}$ we might think that electronic communications is currently available all over the world. It happens that the Internet, for instance, is available in all countries. However, the penetration in Africa is less than $10 \%$.

From the internet usage and population statistics, ${ }^{5}$ we see that Africa has the highest growth in terms of percentage but also the lowest penetration of the world. This can be explained by many factors (poor literacy, low purchasing power, lack of electricity, etc.). In fact, the penetration mentioned here is happening mostly in towns.

\footnotetext{
${ }^{5}$ http://www.internetworldstats.com/stats.htm (accessed July 10, 2016)
}

Still, an approach that does not require an internet connection must be found. This is crucial when conducting capacity building and maintenance programmes. Offline solutions are therefore recommended.

\subsection{Poor data quality and availability from local institutions}

Given the issue raised above, accessing data electronically in African countries will not be easy. However, we need the field data to be available when designing a project. Furthermore, these data should be accurate. Oftentimes our government institutions do not have the necessary means to collect appropriate data in the field and store them or disseminate them. Sometimes, the information available might not be in the form we need. This requires an onsite approach to ensure we collect the relevant information. A detailed understanding for each household's energy requirements for instance should be known to allow for an appropriate micro-grid design. A long series of river gage data is necessary for micro-hydropower plant design. However, small rivers are not generally equipped with gaging stations. When they exist, some data are of questionable accuracy [10] because of the acquisition method. In most cases, institutions do not have the required equipment. We generally rely on international institutions because they fund data collection and make the collected data available, usually online.

The total micro/mini hydropower potentials of many countries have yet to be assessed. When data are available, dissemination is another issue. Designing a micro hydro plant can begin upstream with the investigation on site to locate a potential site. Even if we overcome all the difficulties mentioned above and when everything is technically sound, the governance of the country might be another issue. ${ }^{6}$

In fact, it is important to consider the environment and the governance of the country when planning these projects. This indicates that project development in Africa requires a non-classical approach. To ensure the success of the projects, some sensitive aspects should not rely on officials.

\subsection{Electrification}

It is obvious that there is either no electricity or poor electricity in many remote areas in Africa. The energy usage listed below is for Cameroon [11], but it is similar in most sub-Saharan countries.

- Traditional energy (wood, charcoal, etc.) $65 \%$

- Fossil fuels 21\%

- Electricity $14 \%$

- 100000 hectares of forest are consumed each year

$-98 \%$ of households in savanna regions use only wood for energy

- $65 \%$ of public schools do not have access to electricity

- $68 \%$ of health centres do not have access to electricity

$-64 \%$ of potable water systems are lacking energy

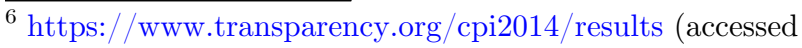
January 4, 2016)
} 


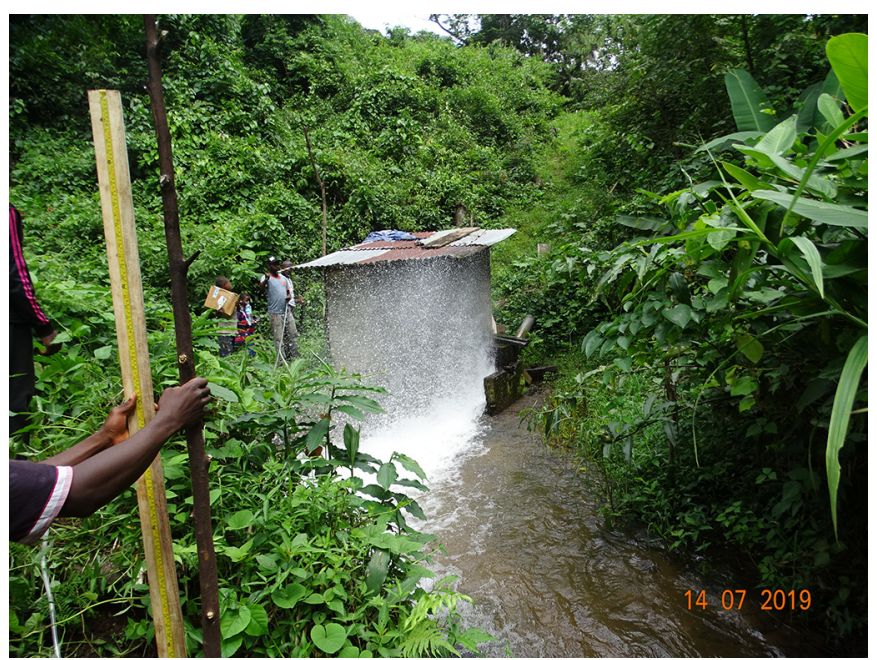

Fig. 3. Micro hydro plant at Firadou in Guinea (PhotoJ. Kenfack).

Many countries are experiencing selective power cuts in the cities, but those really suffering from poor or no electricity are in rural area. In fact, less than $50 \%$ of rural area is electrified in sub Saharan Africa. ${ }^{7}$

\section{Existing electrification technology}

Depending on the site, several solutions can be implemented. There are micro plants from hydro, solar, thermal and biomass.

\subsection{Micro hydro}

Several micro hydro plants are actually running in many villages. Despite the poor efficiency and the poor quality of electricity, they manage to run television, other lowconsumption equipment and good lighting.

While some plants are well designed, the majority are facing many technical problems. Because of the low cost, they are often developed without regard to technical specifications, leading to very poor efficiency as depicted in Figure 3 (high losses with a micro Pelton turbine) and Figure 4 (lack of a flushing system).

The turbines and generators are another issue. There are no up-to-date manufacturers of turbines in the subSaharan part of the continent, but people struggle to do what they can with the means they have. Adapted crossflow and micro pelton turbines are locally manufactured using a traditional workshop equipped with basic machines (old milling machines, lathes, welding, forge) regardless of the efficiency it might have. Because of poor equipment, for instance, buckets for micro pelton turbines are often made of melted aluminium. They are weak, but strong enough to produce several kilowatts, which is enough to meet the local demands in most remote areas. Of course, they do not last, but that is another issue.

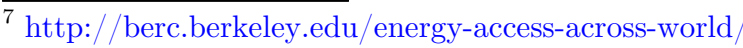

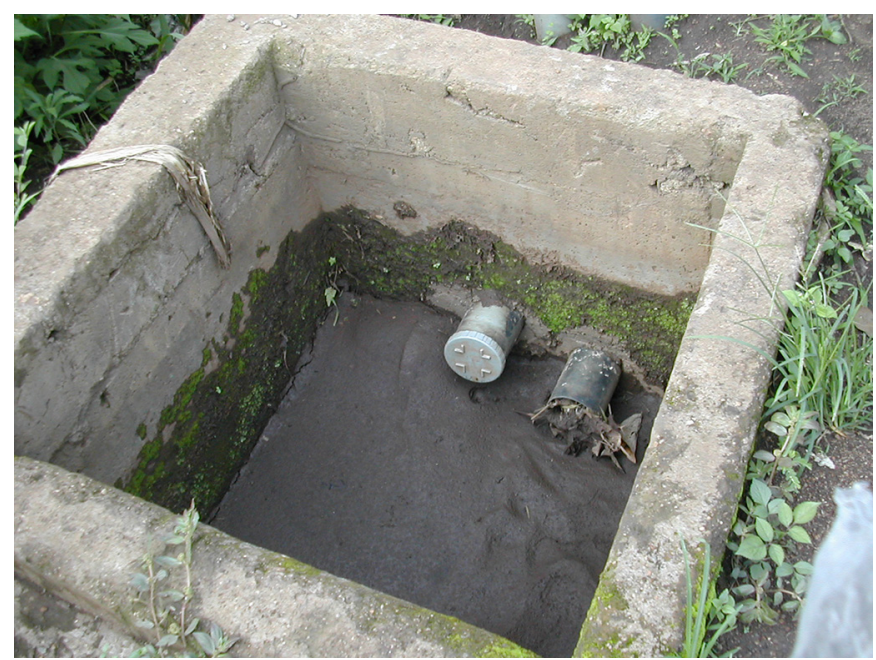

Fig. 4. Forebay with wrong pipe type and mud in BapiCameroon (Photo J. Kenfack).

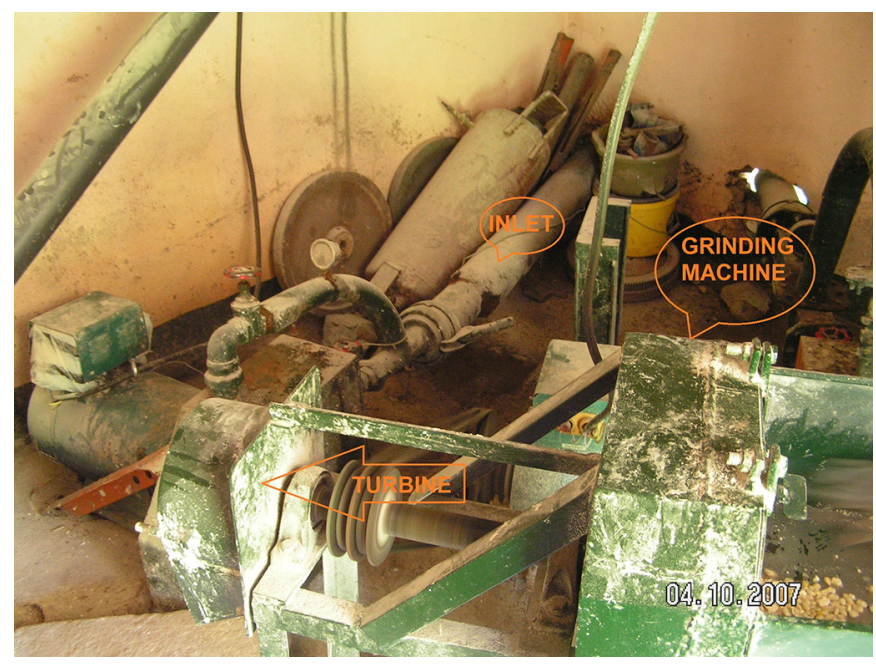

Fig. 5. Locally made micro pelton connected to a grinding machine at Batocha Cameroon (Photo J. Kenfack).

When electricity is not a must for driving force, direct coupling with the turbine shaft is also used to meet some mechanical demands, as depicted in Figure 5. This type of solution is of course local, but it prevents them from generating electricity and then reusing it to run electrical motors connected to a grinding machine, for instance. This approach is also motivated by the fact that ensuring a stable frequency and regulation of the voltage is a large issue. In fact, they are facing serious problems to regulate either the flow discharge or the loads. The only way for the case depicted in Figure 5 is to manually adjust the vanes when visiting the plant. This can only lead to poor values of the operating parameters.

Some plants are made with good equipment. However, when a serious maintenance issue arises, local people cannot solve it because of poor training and availability of spare parts. Foreign aid is often required. 


\subsection{Solar}

Many solar systems are installed, and most of them are running just fine, even if they should be running better. Unlike hydropower, the main solar electric system components such as solar panels, regulators, batteries, cables, lamps and other equipment cannot be homemade. This means that the success of a project mainly relies on the design. We should therefore stress the methods and/or local environment when sizing. Most of the time, the size of the panels do not match with the size of the batteries. One component is over- or under-sized with respect to another and the end use. When the batteries are oversized, they operate very well when commissioning and for some time at the beginning of the project. Later, they experience frequent deep discharge, which is very harmful and which shortens their life expectancy.

It appears that the sizing method utilized was not applicable to the situation. When we went to the telecommunication company to investigate, we realized that they use the static sizing method, using, for instance, an average solar radiation for the region and assuming a constant load. The method was good but could not model annual solar variation together with the fact that the load is from telecommunication traffic, which is dependent on the locality. This led to inappropriate sizing of solar panels and batteries.

Oversizing the solar panels is expensive and we should make the optimal choice. This means that the solar resource should be very well assessed. In this particular case and other cases in general, it is better to use computer software that can make calculations on the basis of hourly data, checking 8760 points in the entire year.

The environment in which the system operates should also be taken into consideration. Figure 6, for instance, shows a solar panel on top of a roof in a village established along the road. The panel is completely covered by dust during the dry season when the solar resource is highly available. An approach ensuring very frequent cleaning (up to daily) should be adopted.

Given the fact that a solar system should last for decades, some basic considerations should also be envisioned, such as the development of the locality in the long run. We can install a very good system and still experience failure simply because of negligence. Figure 7 shows a solar pumping system that is very well designed and installed according to standards in Ndjamena - Chad, but it is currently experiencing the negative impact of shade from trees. In fact, trees are welcome in the city of Ndjamena, where temperatures are up to $50^{\circ} \mathrm{C}$.

\subsection{Wind}

The wind potential is very low $[12]^{8}$ in sub Saharan Africa. However, people are still very courageous and develop many micro wind plants in many areas, regardless of the standards or the efficiency. They simply cope with what is environment-friendly and available at their price. Figure 8

\footnotetext{
8 https://www.geni.org/globalenergy/library/renewableenergy-resources/world/africa/wind-africa/index.shtml (accessed September 18, 2019)
}

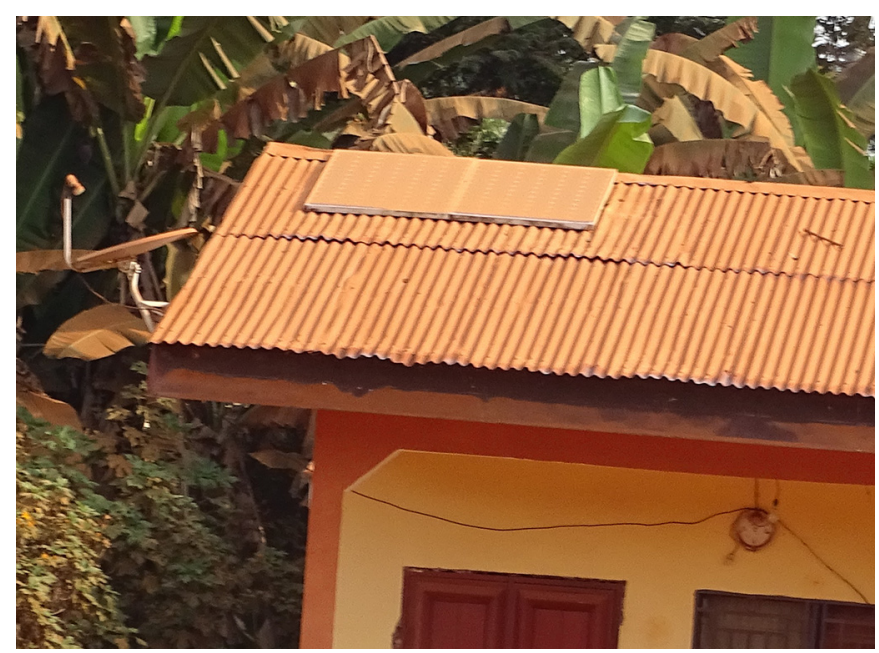

Fig. 6. Solar panel covered with dust in Lomie - Cameroon (Photo J. Kenfack).

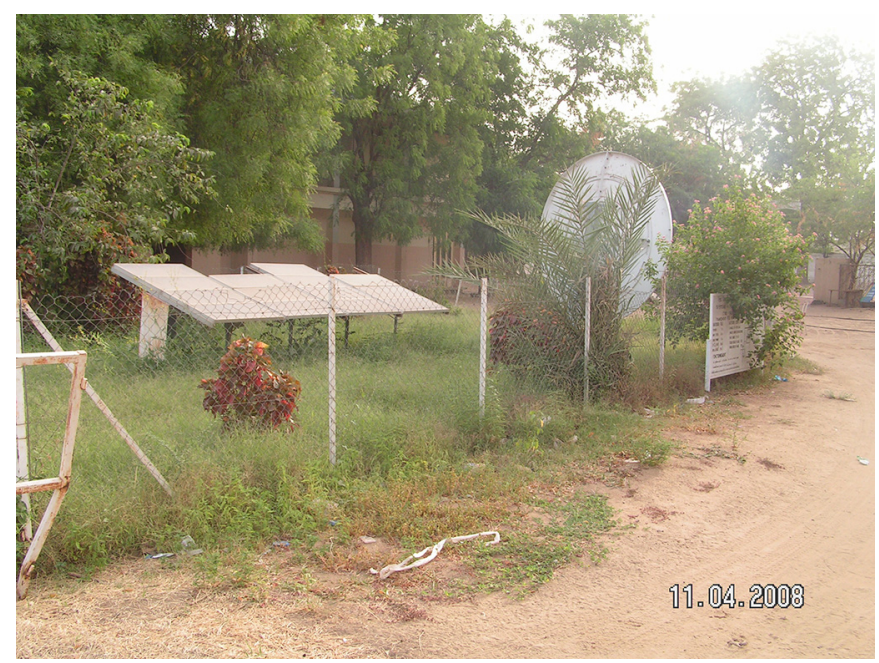

Fig. 7. Shade from trees in a solar pumping system in Ndjamena - Chad (photo J. Kenfack).

shows a system at the top of mount Cameroon $(4100 \mathrm{~m}$ high). The site is very rainy and not that windy because of its position at the equator.

A very low-price local system has been developed here and is known to meet this type of demand. The reality is that people are very enthusiastic when they just imagine having electricity from nature free of charge. We should ensure they continue believing that nature will provide them with electricity and do what is necessary to transform their vision into a dream come true.

\subsection{Hybrid systems}

Micro or small power plants most often used "run of river" for hydro power, "run of wind" for wind power or "run of sun" for solar plants, not involving significant impounding of water or a large battery pack. However, the amount of 


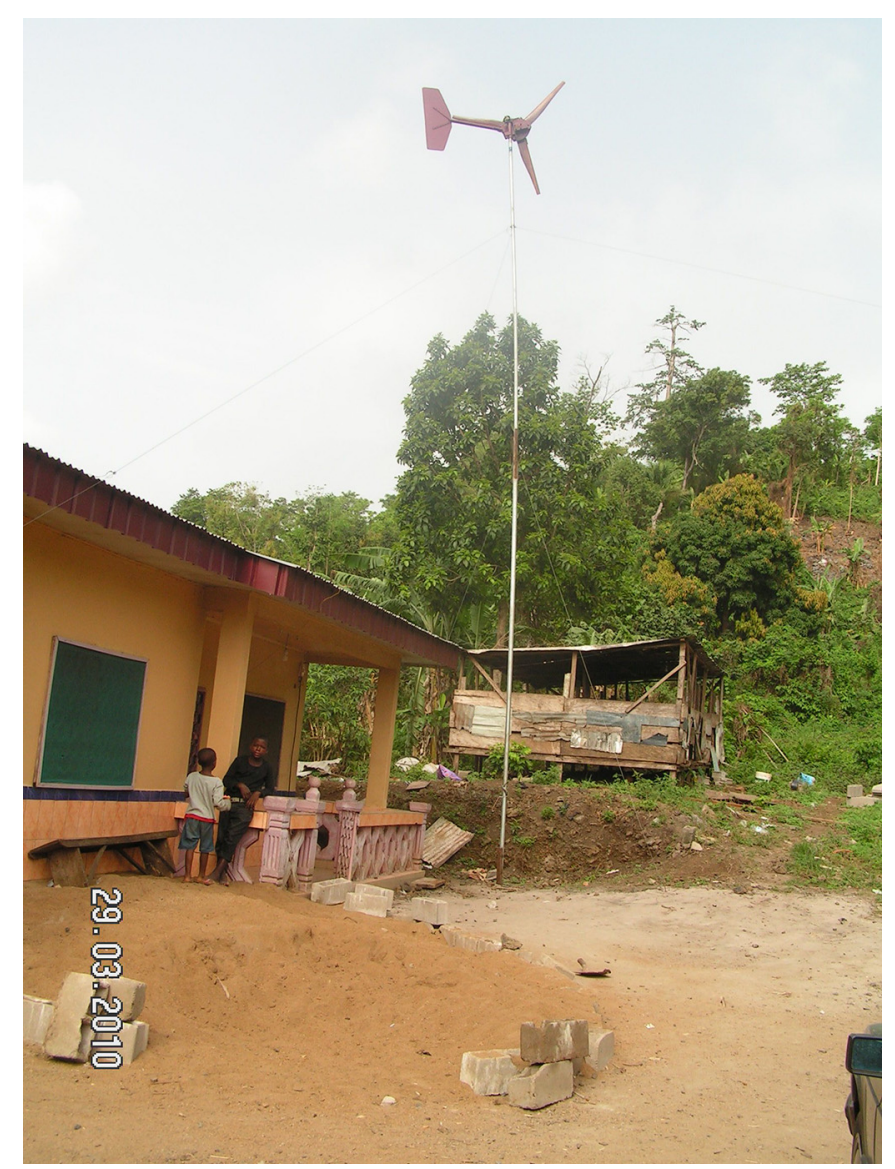

Fig. 8. Locally made wind plant with wooden blades in Limbe Cameroon (photo J. Kenfack).

energy that can be generated depends on the quantity of water/wind/sun available and the variability of the resource throughout the year. In some developing countries of equatorial Africa, the least favourable season for the hydro resource corresponds to the dry season when the solar resource is highly available. Furthermore, the wind resource can be available at any moment during the year. A consistent exploitation of the complementary natures of these sources of energy seems necessary in the effort to maintain a consistent level of electricity production at favourable sites. This approach can make a project more cost effective. The site of Batocha, for instance, in Cameroon, is an interesting case study for its good hydro and solar resources. However, hydro alone cannot satisfy the yearly needs of the population due to effect of the dry and the size of the Batocha River's catchment. The paper written on this topic [13] showed an example of a microhydro-PV-hybrid system, which is sized according to the seasonal variations of both solar and hydro resources. The yearly simulation of the system operation is made via the HOMER ${ }^{9}$ software, which makes it possible to analyse the complementary contribution of both parts of the system and determine the best way to store the energy and the necessity to introduce a diesel generator as a back-up. Of course, depending on the constraints of the location,

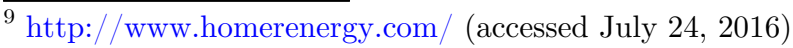

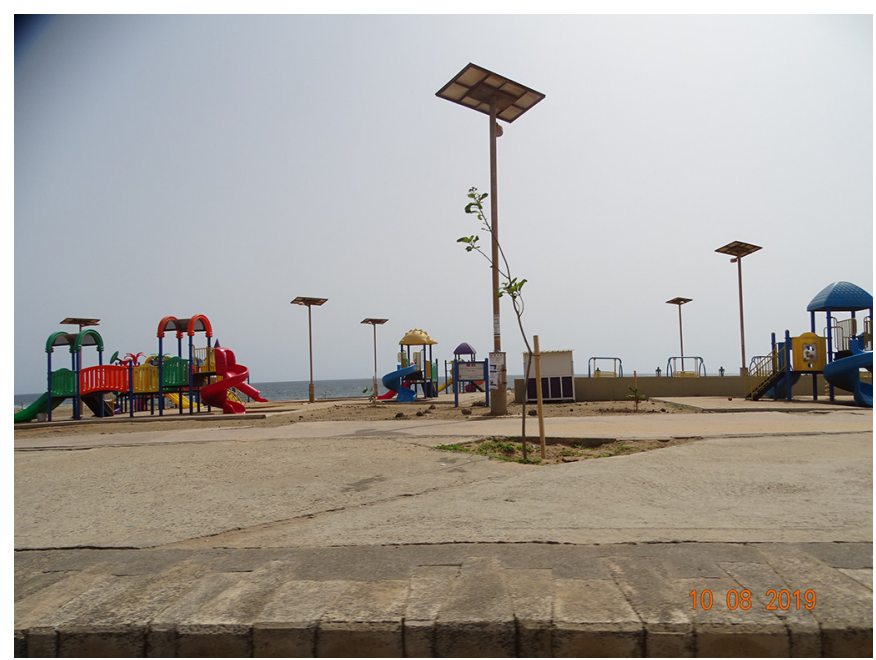

Fig. 9. Public lighting with broken battery system Dakar Senegal (Photo J. Kenfack).

other tools can be used. An assessment of these type of tools was made by Sinha et al. [14], giving a wide range of choices. Biomass is highly available in the equatorial region and can still be part of the system, allowing a wide range of combinations to meet the demands. Before making a decision on the power source to be used in a remote area, an assessment of the opportunity of a hybrid system should be made.

\section{Ensuring project success}

Based on previous failures, we learned numerous lessons [3]. Projects should be government and community-based from their inception. The existing markets should also be assessed to remove barriers for solar diffusion. After-sale services should last up to two years to ensure the initiative has the expected impact. In fact, we should alternate between the dry and the rainy seasons to make sure we experience the impact of dust and heavy rain on the performance of solar panels or hydropower systems. Dissemination of information on successful projects through seminars (regional or national) is another key issue. Successful operators should play a key role in the issue of project dissemination. Technology transfer from successful operators and cooperation between high-quality manufacturers in developing countries is welcome. As mentioned above, the way we conduct capacity building is very important.

\subsection{Learn from some system failures}

Many systems experience failure due to poor design, poor maintenance, or poor construction. From the data collected [3], it is evident that most of the systems suffer from poor skills of the people involved. Figure 9 is an example of a failure due to poor design and maintenance. The battery bank is no longer running. The batteries were of good quality, but the mismatch and cycling led to the permanent deep discharge of the batteries and the premature end of the system life. 


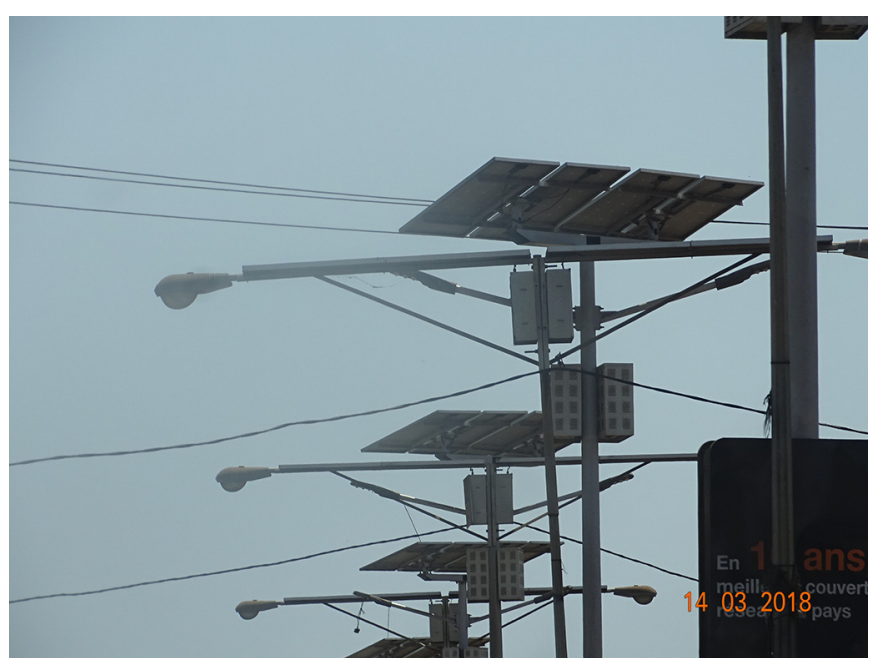

Fig. 10. Two different solar projects on the same street with grid available Conakry - Guinea (Photo J. Kenfack).

Figure 10 is another example of replication of errors from a previous failure in the capital city of Guinea. After failure of a first project, another one was implemented under the same condition without assessing the previous one. This situation highlights the need for good planification of actions from the stakeholders.

This implies no guarantee in terms of efficiency, robustness or quality in general.

Although solar technology is robust and quite simple to develop, poor design is responsible for a great number of failures. Software tools can be used to size the system [13], but the field constraints should be taken into consideration. The average temperature can be as high as $52^{\circ} \mathrm{C}$ and the climate is also very wet. Batteries can be sensitive to high temperatures. Therefore, the chosen battery should be able to withstand hot conditions. Because of poor technical knowledge, people often bypass the solar charge controller when the charge is automatically disconnected under low battery conditions. It is essential to ensure that only qualified personnel can access the solar charge controller. The region around the equator experiences heavy lightning. The system should therefore be protected by appropriate grounding systems and offer overvoltage protection. When a system is newly developed, user loads are constantly increasing, leading to overload and premature breakdown because of deep battery cycling and/or discharge. It is recommended to install an inaccessible overload system to keep the system running within the design load. As much as possible, local or available robust components should be used in order ease the maintenance.

We should hence emphasize on training people correctly from the inception phase. In fact, even if a system is very well designed, poor capacity of a contractor can lead to the improper construction of a plant. When we are in an environment where standards are a big issue, personal skills are an important asset.

We should therefore take the necessary measures to ensure a good level of personal skills in the long run. This

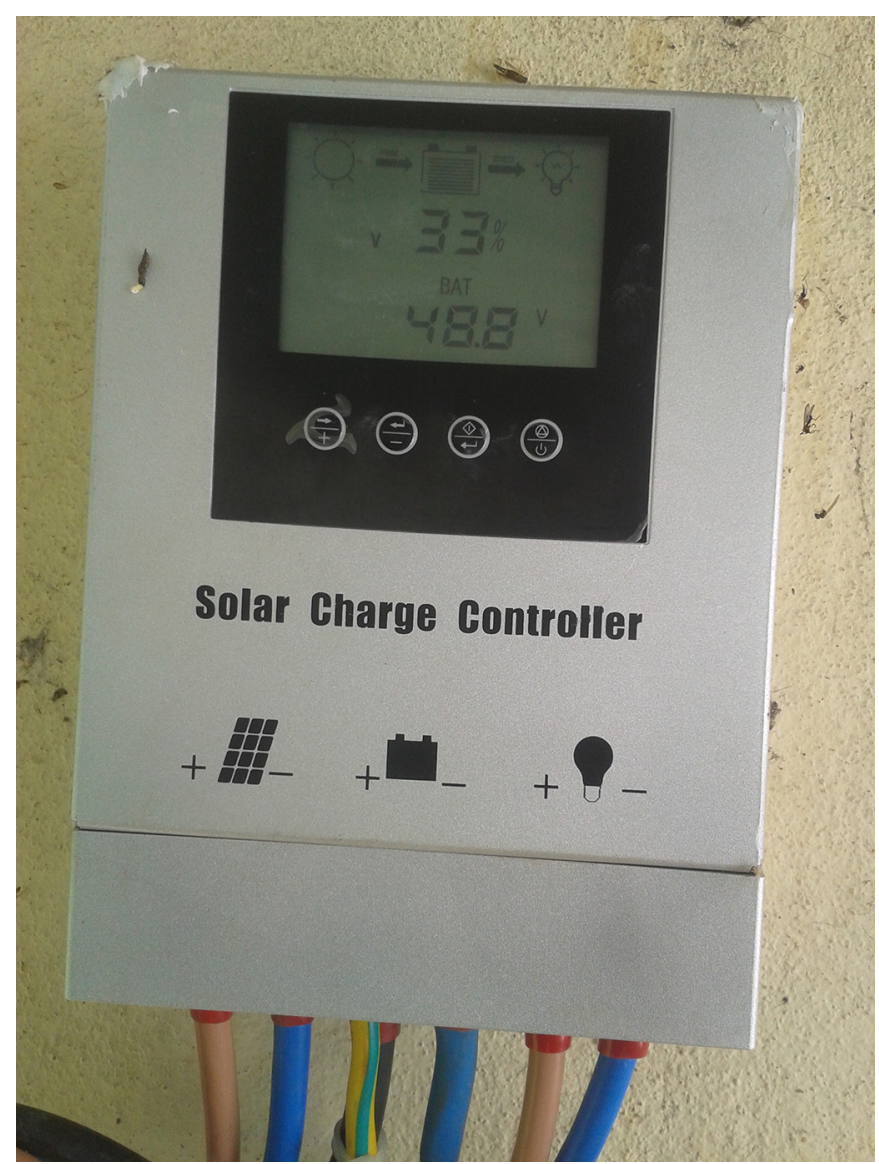

Fig. 11. Unbranded solar charger for the national telecommunication company station at Mengong - Cameroon (Photo J. Kenfack).

can be done through regular assessments of the situation and seminars. By doing so, we can avoid the choice of equipment for which the specifications are not known or do not match the application. This approach will help a country like Guinea in which all the subdivisions are equipped with tens of public lighting solar systems, with less than $20 \%$ running nowadays in many localities. Given the organization, the purchasing power or the economic situation of the region, standards concerning manufactured products most often do not exist. Unbranded equipment such as the device depicted in Figure 11.

\subsection{Need for sustainable renewable energy policy}

In Guinea, a decision to provide all subdivisions with solar systems for public lighting was taken and implemented. Nowadays, less than $20 \%$ of this equipment is running in some localities as stated previously. This means a national plan for dissemination and maintenance of this technology is required and should be set before implementation phase. This can be done through existing training facilities and during plants erection.

In the early 1960s, Cameroon, for instance, had many micro hydro plants under operation in cities like Dschang, 

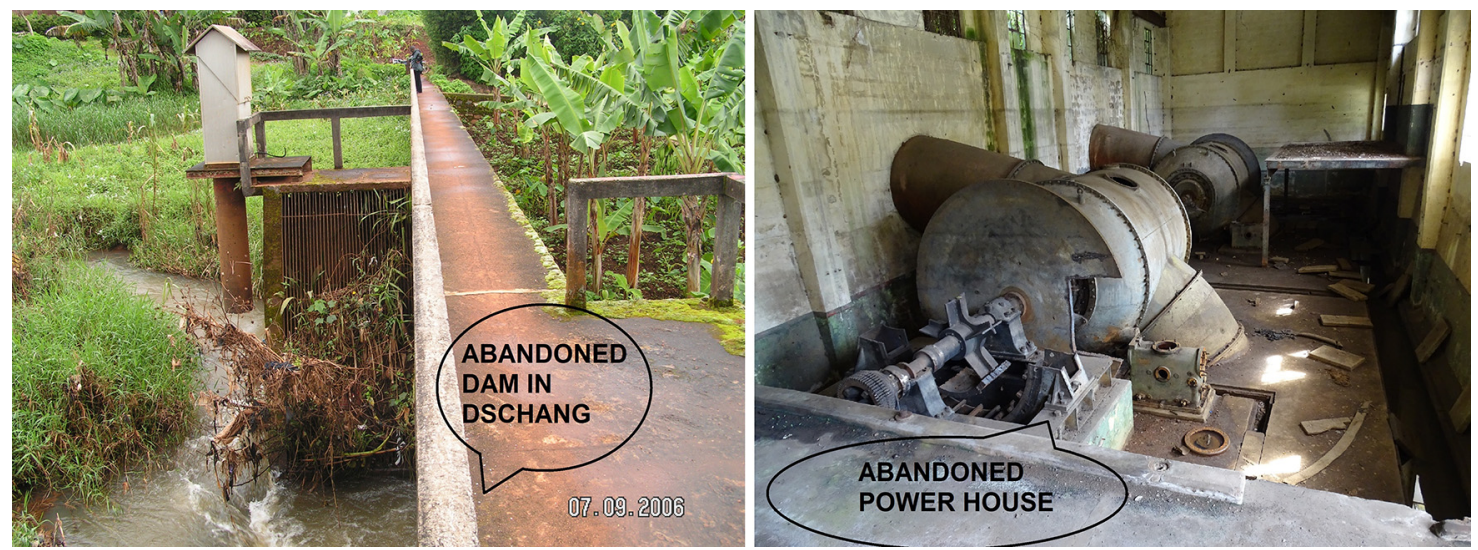

Fig. 12. Abandoned $200 \mathrm{~kW}$ in Dschang and $1000 \mathrm{~kW}$ in Malale - Cameroon (Photo J. Kenfack).

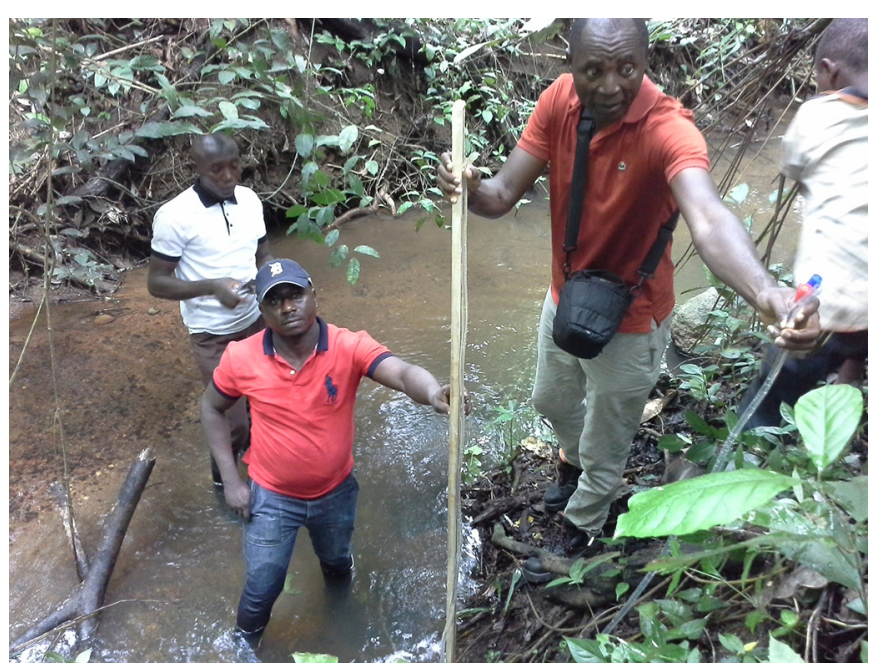

Fig. 13. Field training on head measuring at Firadou - Guinea (Photo J. Kenfack).

Muyuka, Foumban, Kumba. However, the development of large hydro plants led to long distance grid extension to the detriment of micro/small hydro. The micro/small hydro plants were simply shut down. As a consequence, the knowledge required to run micro/small hydro plants was lost. Currently, people are attempting to build again what they lost after $40 \mathrm{yr}$, but at a very high cost because everything has to start almost from scratch. Figure 12 is an example of two abandoned hydro plants built in the years 1960s.

The maintenance of micro/small hydro plants has been neglected, and many of these plants are currently abandoned. Because of the growth of the demand and consequently the important end user voltage drop, people in this region realize today that they made a mistake. The Djoue small hydro plant in Brazzaville also experienced an accident due to negligence.

Micro-hydropower plants have also been developed in some countries, but poor hydro resources and lack of experience have led to the decline of many such plants.

Due to the poor environmental conditions and the lack of local expertise, we emphasise on the capacity building

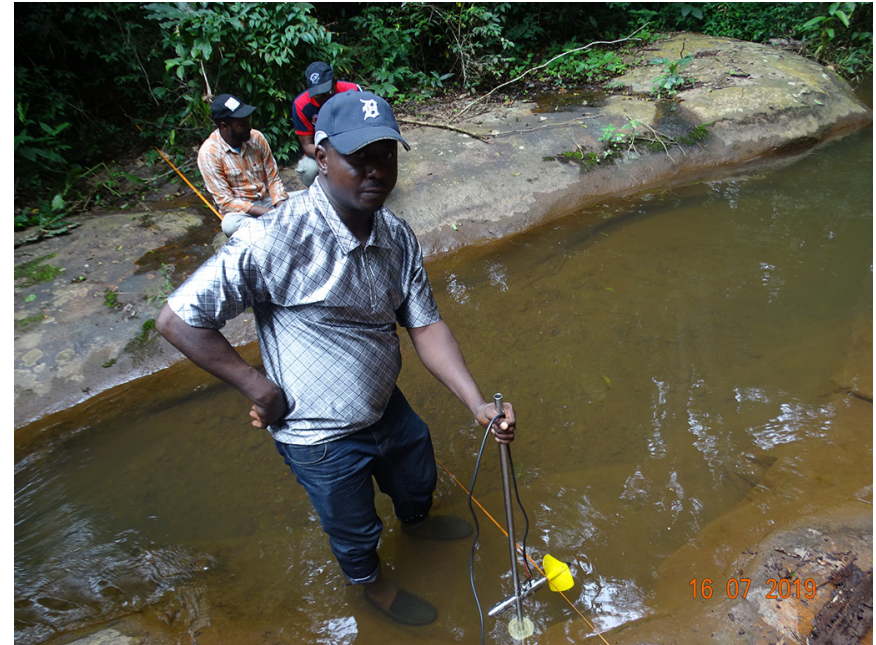

Fig. 14. Field training on discharge measurement at Lola Guinea (Photo J. Kenfack), UNDP project.

with field training as depicted in Figures 13 and 14. The two figures show a successful experience with the stakeholders in Guinea. Once a system is well designed, local companies should be able to properly erect the plant. For this purpose, it is very important to also enhance their capacity. They should also be trained on designing and constructing hydraulic infrastructures. To be more efficient, some micro hydraulic infrastructures obtained from $3 \mathrm{D}$ printers can be used as didactic equipment as we did in Guinea with UNDP. The success of this program has motivated the United Nations Development Program and Africa Development Bank to replicate the project at larger scale in the future.

We should install the simplest system possible with high efficiency. The components should be found in the local market for maintenance purposes and should also be robust, easily repairable and easily transportable. A DC generator from vehicles for system below 2 kilowatts for instance can be used, since it includes the voltage regulation with a wide range of rotational speed. A strong programme on capacity building should be set locally before, during and after the plant development. The 


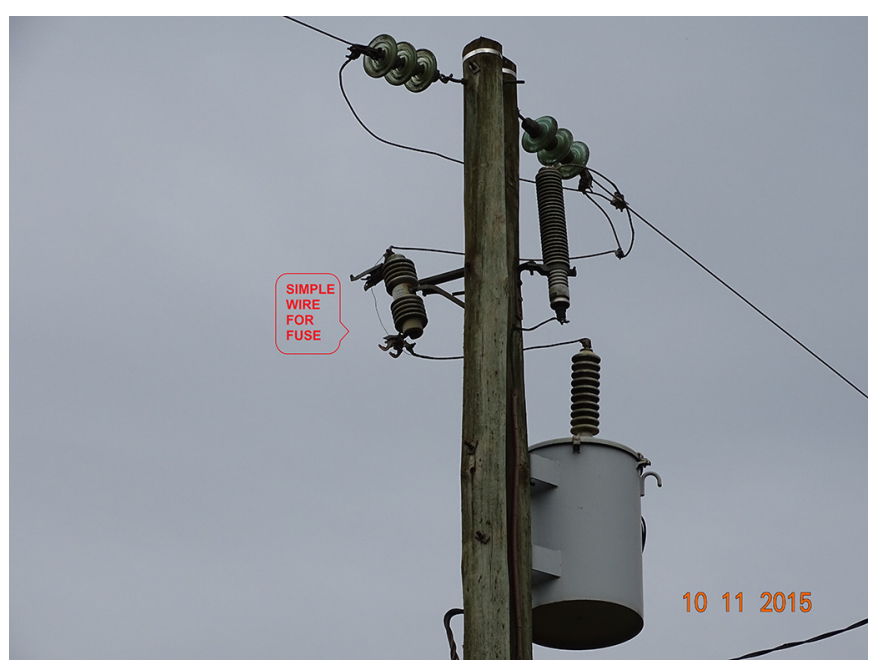

Fig. 15. A 17300 volts single wire ground return system with poor fuse system in Lingang - Cameroon (Photo J. Kenfack).

programme should include the treatment of the poles, the sizing of an electric network including other components of the system, the protection of the electrical circuit, the maintenance of the equipment and each part of the system. For low head systems, i.e., below $10 \mathrm{~m}$, an Archimedes screw can be envisaged.

Minigrids are often made with wooden poles because they are cheaper than concrete poles or galvanized poles, but they should undergo special treatment to protect them against weevils. Even wooden pole treatment is suffering from insufficient regulation. Once more, a national plan and regulations should be set to ensure the sustainability of the projects. Madriz-Vargas et al. [15] from a successful case study in Panama pointed out other key measures to be taken in order to ensure the sustainability of the projects.

Ownership of assets inside the community, high levels of involvement by the community are among the strong recommendations. Constructing good power lines is another issue. In fact, the poor regulation or standards mentioned upstream is negatively affecting the quality of the power lines. We experience poor equipment installations from high voltage protection (see Fig. 15) to end user equipment.

\section{Results and discussion}

We found that the environment in a developing country is not an easy one in which to operate. This means that the approach should not be classic. In the absence of specific studies in all countries for rural areas like the one made by Mdee et al. [16] for larger plants, it is important to promote capacity building and train the main people involved on how to develop micro renewable energy plants using a hands-on method. Still, we should study the social context in order to make sure the programme matches with the environment. Using local people with local language skills can be a challenge. Foreign values are sometimes vulnerable to misunderstanding. It is therefore important to integrate with the values that might apparently be far

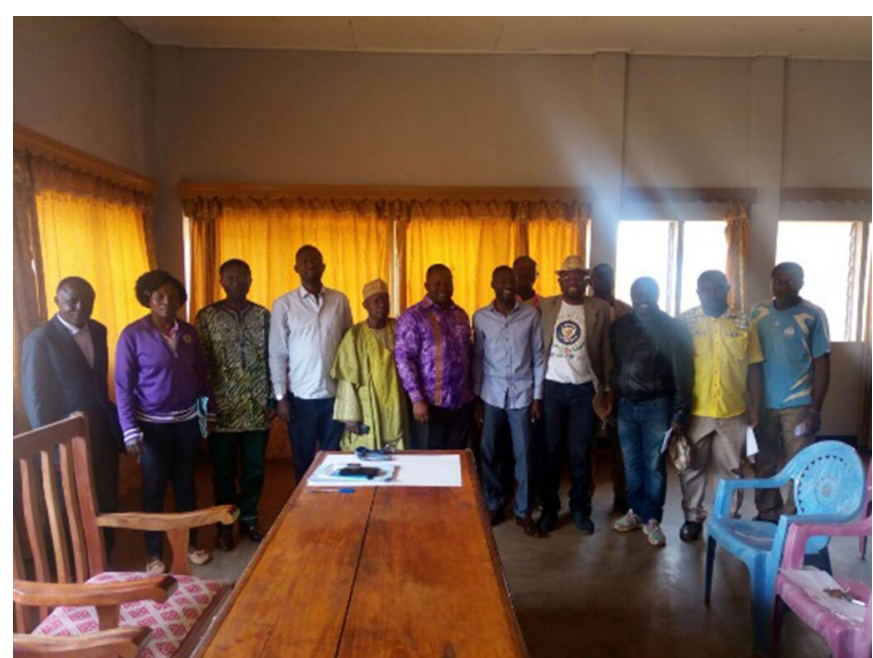

Fig. 16. Stakeholders' consultation for a micro hydro site in Dschang - Cameroon.

different from what we are used to. It is a question of whether one regards the glass as being half full or as being half empty.

In many countries, there are poor guidelines for those who develop micro-hydropower and solar plants. When available, the literature does not address well enough the specific issues encountered in remote areas, such as the method of capacity building, ungagged rivers, and maintenance. In places where there is more than one resource available, suggestions are made together with tools to size and design a hybrid system to make best use of the renewable energy potential. This will contribute to fill the gap between the abundant solar and hydro resources in the continent and its poor development compared to the rest of the world. Most of the systems currently are made of thermal (fossil) plants together with renewable energy plants. However, improvement to this approach can still be made through dissemination of the technology to be implemented. Here again comes the importance of pilot projects. We have implemented the methodology and we got satisfactory result from the micro hydro case study depicted in Figures 16 and 17 . We got funds raised from international institutions for this successful example. The process of plant erection is ongoing.

Sharing the cause of failed projects will help avoid repeating errors and make operators successful and ensure the correct promotion of renewable energy [17]. The system should be designed to be simple but also robust and easy to repair. This can lead to less efficient systems, but they will be robust enough to withstand poor operating conditions. All stakeholders should be involved at early stage. Several tools should be made available for hydropower resource estimation, solar radiation estimation and appropriate plant sizing methods. Some types of data collection (gaging station on a river for instance) can be community based, as well as plant construction and maintenance, which should be taught using pilot projects. In any case, it is important to avoid simply dropping a project in an area and expecting the people to take ownership and run it properly. 


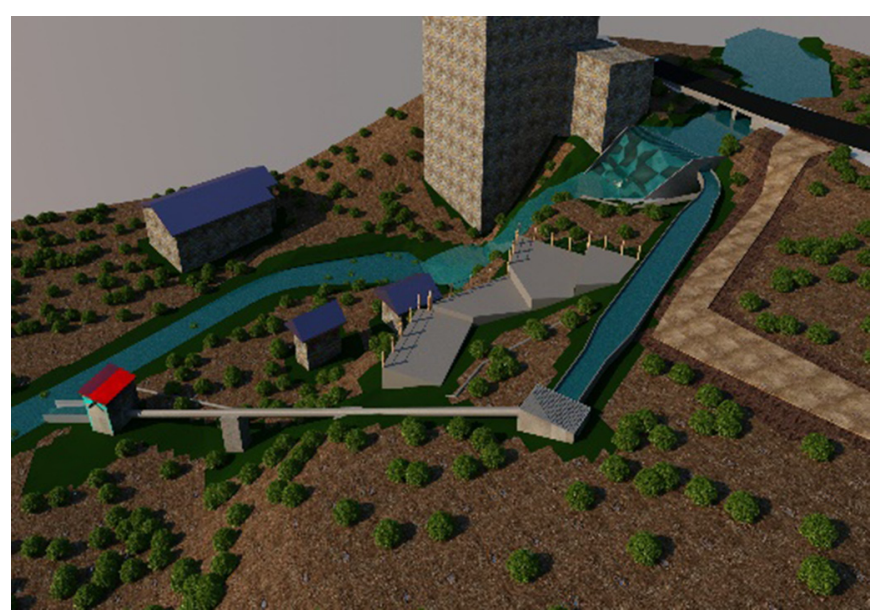

Fig. 17. 3D model of Lefock micro hydro site studied in Dschang - Cameroon.

\section{Conclusions}

Although the overall situation in the continent is far from ideal, there is still a room for good renewable energy development. Given the low specific demand, micro renewable energy plants are suitable for remote areas in Africa if adequately developed. Implementing this technology properly will lead to the sustainable development of rural communities. It is crucial to make the correct choices in terms of technology and tools, institutional support and capacity building. Collaborations with relevant manufacturers in foreign countries are necessary, as many solutions are available and only require proper foresight in terms of implementation. It is critical to address the issue regionally and not just locally. The assessment of the social environment to identify potential obstacles and look for ways to mitigate them is required. Sizing, choosing appropriate components, technology and maintenance, method of capacity building, and after-sale service are the core issues to be addressed. Prior to all, a good assessment of the socioeconomic situation and the culture is needed. After assessing the situation and based on the lessons learned, we should be able to make suggestions to help the countries in Africa develop specific capacity building aimed at developing good teams to sustain appropriate energy development and hence increase the status of solar and hydropower energy sources to better contribute to the fight against climate change. This approach was tested in a pilot city (Dschang) in Cameroon and we got satisfactory result. These suggestions should be regionally focused in order to maximize their impact.

\section{References}

1. P.O. Oshokoya, M.N.M. Tetteh, Mine-of-the-future: How is Africa prepared from a mineral and mining engineering education perspective, Resour. Policy 56, 125-133 (2018)

2. B.A. Gyampoh, Promoting research in sustainable energy in Africa, in: Sustainable Hydropower in West Africa - The Circle Model, Academic Press, MA, USA, 2018, pp. 29-36

3. J. Kenfack, O. Videme Bossou, J. Voufo, S. Djom, Addressing the current remote area electrification problems with solar and microhydro systems in central Africa, Renew. Energy 67, 10-19 (2014)

4. A. Alireza, W.V. Kau-Fui, Analysis of renewable energy development to power generation in the United States, Renew. Energy 63, 153-161 (2014)

5. H. Lund, The implementation of renewable energy systems. Lessons learned from the Danish case, Energy 35, 4003-4009 (2010)

6. http://www.uis.unesco.org/literacy/Pages/data-release-map2013.aspx (accessed June 15, 2016)

7. https://fr.wikipedia.org/wiki/Liste_des_pays_par_taux d'alphab\%C3\%A9tisation\#/media (accessed January $\overline{2}$, 2016)

8. A. Thomas Young, J.R. Cole, D. Denton, Improving technological literacy, Sci. Technol. 18, 73-79 (2002)

9. B. Piper, S.S. Zuilkowski, D. Kwayumba, A. Oyanga, Examining the secondary effects of mother-tongue literacy instruction in Kenya: Impacts on student learning in English, Kiswahili, and mathematics, Int. J. Educ. Dev. 59, 110-127 (2018)

10. J.C. Olivry, Fleuves et rivières du Cameroun. Sine loco. Collection Monographies Hydrologiques ORSTOM N $\mathrm{N}^{\circ}$, 1986 , p. 733

11. Government of Cameroon, National Energy Plan for poverty alleviation, 2005

12. D. Mentis, S. Hermann, M. Howells, M. Welsch, S.H. Siyal, Assessing the technical wind energy potential in Africa a GISbased approach, Renew. Energy 83, 110-125 (2015)

13. J. Kenfack, F.P. Neirac, T.T. Tatietse, D. Mayer, M. Fogue, A. Lejeune, Microhydro-PV-hybrid system: Sizing a small hydro-PV-hybrid system for rural electrification in developing countries, Renew. Energy 34, 2259-2263 (2009)

14. S. Sinha, S.S. Chandel, Review of software tools for hybrid renewable energy systems, Renew. Sustain. Energy Rev. 32, 192-205 (2014)

15. R. Madriz-Vargas et al., Community renewable energy in Panama: a sustainability assessment of the "Boca de Lura" PV-Wind-Battery hybrid power system, Renew. Energy Environ. Sustain. 2, 18 (2017)

16. O.J. Mdee1, T.K. Nielsen, C.Z. Kimambo, J. Kihedu, Assessment of hydropower resources in Tanzania. A review article, Renew. Energy Environ. Sustain. 3, 4 (2018)

17. J. Kenfack, J. Lewetchou, O.V. Bossou, E. Tchaptchet, How can we promote renewable energy and energy efficiency in Central Africa? A Cameroon case study, Renew. Sustain. Energy Rev. 75, 1217-1224 (2017)

Cite this article as: Joseph Kenfack, Joseph Voufo, Paul Salomon Ngohe Ekam, Jeanine K. Lewetchou, Urbain Nzotcha, Overcoming local constraints when developing renewable energy systems for the electrification of remote areas in Africa, Renew. Energy Environ. Sustain. 5, 1 (2020) 